\title{
The Effects of Trimetazidine on Heart Rate Variability in Patients with Heart Failure
}

Yilmaz Gunes, Unal Guntekin, Mustafa Tuncer, Musa Sahin

Yuzuncu Yil University, Faculty of Medicine, Cardiology Department, Van, Turkey.

\begin{abstract}
Summary
Background: Reduced measures of heart rate variability (HRV) have been shown to be related with prognosis in heart failure. Chronic administration of trimetazidine in addition to the conventional therapy has been shown to improve functional class and left ventricular functions of heart failure patients.
\end{abstract}

Objective: To assess the effects of trimetazidine on HRV in optimally treated patients with heart failure of ischemic origin.

Methods: Trimetazidine $20 \mathrm{mg}$ three times/day was added to therapy of 30 patients with heart failure being treated with angiotensinogen converting enzyme inhibitors or angiotensin receptor blockers, carvedilol, spironolactone, digitalis and furosemide. The etiology of heart failure was coronary artery disease in all patients. Patients were evaluated with echocardiography and 24-hour heart rate variability analysis before and 3 months after addition of trimetazidine.

Results: Mean left ventricular ejection fraction (LVEF) significantly increased after the addition of trimetazidine (33.5 $\pm 5.1 \%$ to $42.5 \pm 5.8 \%, p<0.001)$. Of the HRV parameters, SDNN $(97.3 \pm 40,1$ to $110.5 \pm 29,2$ msecs, $p=0.049)$ and SDANN (80.5 $\pm 29,0$ to $98.3 \pm 30,5$ msecs) were significantly increased after trimetazidine treatment. Baseline SDNN was significantly correlated with baseline LVEF $(r=0.445, p=0.023, p=0.008)$ and the increment in SDNN was correlated with increase in LVEF $(r=0.518, p=0.007)$.

Conclusions: Adding trimetazidine to optimal medical therapy in patients with heart failure of ischemic origin may improve heart rate variability in association with improved left ventricular ejection fraction. (Arq Bras Cardiol 2009; 93(2):145-148)

Key Words: Trimetazidine / administration and dosage; heart rate; heart failure.

\section{Introduction}

Patients with chronic heart failure (CHF) present autonomic dysfunction with activation of the sympathetic nervous system and reduction in parasympathetic activity ${ }^{1,2}$. Analysis of the heart rate variability (HRV) is a reliable and reproducible technique for assessing autonomic activity in patients with cardiovascular diseases ${ }^{3-6}$. Reduced measures of heart rate variability have been shown to be related with prognosis in heart failure ${ }^{7,8}$. Several investigators have demonstrated that measurements of HRV can be used to evaluate the effect of angiotensin-converting enzyme inhibitors and $\beta$-adrenergic receptor antagonists on cardiac autonomic activity in patients with heart failure ${ }^{9,10}$. Trimetazidine is a metabolic agent with anti-ischemic properties operating independently of any hemodynamic changes. Previous studies have also suggested that trimetazidine modulates the postmyocardial infarction autonomic control of HRV, that is, that it reduces sympathetic overactivity and augments vagal influence ${ }^{11,12}$. Trimetazidine acts as a partial inhibitor of fatty acid oxidation and in turn,

Mailing Address: Yilmaz Gunes •

Yuzuncu Yil University, Faculty of Medicine, Cardiology Department, Van, Turkey E-mail: yilmazleman@yahoo.com

Manuscript received on 21/04/2008; reviewed manuscript received on 17/07/2008; accepted on 15/10/2008. trimetazidine stimulates glucose oxidation. In heart failure, similar to what happens during acute myocardial ischemia, glucose and lactate oxidation are decreased and fatty acid oxidation is increased, increasing the oxygen requirement ${ }^{13}$.

In this study we aimed at assessing the effects of trimetazidine, added to conventional heart failure treatment, on HRV in patients with heart failure.

\section{Methods}

Thirty patients with heart failure and New York Heart Association (NYHA) functional class II or III who were already receiving optimal heart failure treatment consisting of angiotensinogen-converting enzyme inhibitors or angiotensin receptor blockers, carvedilol, spironolactone, digitalis and furosemide were included in the study. The etiology of the heart failure was coronary artery disease documented by coronary angiography in all patients. Following baseline echocardiographic examination, trimetazidine, at a dose of $20 \mathrm{mg}$ three times/day, was added to the therapy and patients were reevaluated 3 months later. Exclusion criteria were; NYHA class IV, acute myocardial infarction in the previous 3 months, atrial fibrillation, LV ejection fraction (LVEF) $>40 \%$, severe valvular heart disease, alcoholic cardiomyopathy, 


\section{Original Article}

pacemakers, renal failure (serum creatinine $>2.0 \mathrm{mg} / \mathrm{dL}$ ), chronic lung disease or any systemic disorder and use of additional drugs such as antiarrhythmics. The study was approved by hospital Ethics Committee and patients gave their written informed consent.

The echocardiographic examination was performed at rest, with the patient on the left lateral decubitus position, using a commercially available echocardiographic device (Vivid 3, General Electric) with a $3 \mathrm{MHz}$ transducer, by two experienced echocardiographists who were blinded to the clinical data. Using M-mode echocardiography, long-axis measurements were obtained at a level distal to the mitral valve leaflets, according to current recommendations ${ }^{14}$. Left ventricular ejection fraction was calculated via modified biplane Simpson's method from apical four and two chamber views. Measurements were made off-line on three separate beats and then averaged for all parameters. During the entire echocardiographic study, a single-lead electrocardiogram was continuously recorded.

\section{Heart Rate Variability Analysis}

Twenty-four-hour ambulatory electrocardiogram Holter monitoring was performed using Aria digital Holter recorder (Spacelabs healthcare). The recordings were analyzed with special computer software (Impresario Solo package). All recordings were visually examined and manually overread to verify beat classification by two experienced examiners who were blinded to the clinical data. Only recordings with at least 20 hours of data and $80 \%$ or more of quantified sinus beats were included in the analysis. Abnormal beats and areas of artifact were automatically and manually identified and excluded from the analysis. Moreover, the longest and

Table 1 - Baseline characteristics of the study patients $(n=30)$.

\begin{tabular}{lc}
\hline Age years & $59.6 \pm 10.2$ \\
\hline Male sex & $24(80.0 \%)$ \\
\hline Coronary artery disease & $30(100.0 \%)$ \\
\hline Diabetes mellitus & $7(23.3 \%)$ \\
\hline Hypertension & $16(53.3 \%)$ \\
\hline Smoking history & $20(66.7 \%)$ \\
\hline
\end{tabular}

Table 2 - Blood pressures, functional class and LVEF of the patients.

\begin{tabular}{cccc}
\hline & Pretreatment & Post-treatment & P value \\
\hline Systolic BP $(\mathrm{mmHg})$ & $122.3 \pm 16.7$ & $120.4 \pm 15.3$ & 0.686 \\
\hline Diastolic BP $(\mathrm{mmHg})$ & $78.5 \pm 11.4$ & $77.7 \pm 12.1$ & 0.785 \\
\hline NYHA class I & $19(63.3 \%)$ & $24(80 \%)$ & 0.252 \\
class II & $9(30.0 \%)$ & $6(20.0 \%)$ & \\
class III & $2(6.7 \%)$ & 0 & \\
\hline LVEF $(\%)$ & $33.5 \pm 5.1$ & $42.5 \pm 5.8$ & $<0.001$ \\
\hline
\end{tabular}

BP: blood pressure, LVEF: left ventricular ejection fraction shortest true normal-to-normal intervals were identified for each recording in order to exclude all beats outside this range from the heart rate variability (HRV) analysis. The following parameters were used in evaluation of HRV in time domain: (1) Standard deviation of all normal-to-normal intervals (SDNN [milliseconds]); (2) Standard deviation of mean of all normalto-normal intervals in all consecutive 5-min segments of the entire recording (SDANN [milliseconds]); (3) The root mean square of differences between adjacent normal-to-normal intervals (rMSSD [milliseconds]); (4) The percentage of R-R intervals with more than 50 milliseconds variation ( $\mathrm{pNN} 50$ ); (5) Standard deviation of differences between successive normal-to-normal intervals (SDSD [milliseconds]).

\section{Statistics}

Data were presented as mean \pm standard deviation (SD). Using an SPSS package 10.0 (SPSS Inc., Chicago, Illionis, USA) the changes in parameters after treatment were compared with paired t-tests. Pearson's correlation analysis was used to assess the correlation between variables. A two-tailed $p$ value $<0.05$ was considered significant.

\section{Results}

The mean age of the patients was 59.6 \pm 10.2 (38-75) years and 24 of them (80.0\%) were males. Seven (23.3\%) patients had diabetes and 16 (53.3\%) had hypertension (Table 1). Mean systolic blood pressure was $122.3 \pm 16.7 \mathrm{mmHg}$ and mean diastolic pressure was $78.5 \pm 11.4 \mathrm{mmHg}$. No significant changes occurred regarding blood pressures. A significant increase in mean LVEF was observed after the addition of trimetazidine $(33.5 \pm 5.1 \%$ to $42.5 \pm 5.8 \%, \mathrm{p}<0.001)$ (Table 2$)$. Of the HRV parameters, SDNN and SDANN were significantly increased after trimetazidine treatment (Table 3, Figure 1, Figure 2). Baseline SDNN was significantly correlated with baseline LVEF $(r=0.445, p=0.023)$. Also, the increment in SDNN was correlated with the increase in LVEF $(r=0.518$, $\mathrm{p}=0.007$ ).

\section{Discussion}

In the present study, we observed that trimetazidine improved LVEF and HRV in patients receiving optimal treatment for heart failure of ischemic origin. Heart rate variability is a simple and noninvasive method used to identify vagal or sympathetic control of heart rate $e^{15,16}$. Changes in the vagal or sympathetic tone of heart rate assessed by HRV analysis have been associated with mortality, arrhythmias and sudden cardiac death, particularly after acute myocardial infarction and heart failure $7,8,17-19$. The chronic administration of trimetazidine in addition to the conventional therapy, in overall terms, has been shown to improve functional class and LV functions of heart failure patients ${ }^{20-22}$. Previous studies have also suggested that trimetazidine modulates the autonomic control of HRV, i.e., that it reduces sympathetic overactivity and increases vagal influences ${ }^{11,12,23}$.

Heart failure is associated with autonomic dysfunction, which can be quantified by measuring HRV. A reduction in SDNN identified patients at high risk of death ${ }^{7,8}$. In the 
Table 3 - Twenty-four hours heart rate variability parameters.

\begin{tabular}{lccc}
\hline & Pretreatment & Post-treatment & P value \\
\hline Mean heart rate (bpm) & $74.3 \pm 10.3$ & $73.9 \pm 10.3$ & 0.819 \\
\hline SDNN (msec) & $97.3 \pm 40.1$ & $110.5 \pm 29.2$ & 0.049 \\
\hline rMSSD (msec) & $42.2 \pm 20.1$ & $46.5 \pm 22.0$ & 0.323 \\
\hline PNN50 (\%) & $9.1 \pm 8.1$ & $7.7 \pm 5.9$ & 0.256 \\
\hline SDANN (msec) & $80.5 \pm 29.0$ & $98.3 \pm 30.5$ & 0.008 \\
\hline SDSD (msec) & $40.2 \pm 31.9$ & $38.9 \pm 19.2$ & 0.776 \\
\hline
\end{tabular}

SDNN: Standard deviation of all normal-to-normal intervals, rMSSD: root mean square of differences between adjacent normal-to-normal intervals, PNN50: percentage of $R$-R intervals with more than 50 milliseconds variation, SDANN: Standard deviation of mean of all normal-to-normal intervals, SDSD: Standard deviation of differences between successive normal-to-normal intervals.

prospective analysis of the UK-Heart study, the evaluation of 433 outpatients with congestive heart failure (NYHA functional class I to III; mean LVEF $0.41 \pm 0.17$ ), showed that the reduction in SDNN was a more powerful predictor of death risk, due to progressive heart failure, than the other conventional clinical measurements ${ }^{7}$. Aronson et $\mathrm{al}^{24}$ found SDNN and SDANN to be useful predictors of survival after discharge in patients with decompensated heart failure. Therefore, our findings of increased SDNN and SDANN after the addition of trimetazidine to optimal medical therapy may have important clinical implications.

Trimetazidine has been reported to have a favorable effect on HRV parameters, explained by decreases in the sympathetic and increases in the parasympathetic activity in acute ischemic conditions ${ }^{11,23}$. Trimetazidine exerts its anti-ischemic properties without affecting myocardial oxygen consumption and blood supply ${ }^{25-27}$. Trimetazidine affects myocardial substrate use by inhibiting oxidative phosphorylation and by shifting energy production from free fatty acids (FFA) to glucose oxidation ${ }^{27}$. The beneficial effect of this agent has been attributed to preservation of phosphocreatine and adenosine triphosphate (ATP) intracellular levels and reduction of cell acidosis, calcium overload and free radical-induced injury caused by ischemia ${ }^{26-32}$. In heart failure, similar to what happens during acute myocardial ischemia, glucose and lactate oxidation are decreased and fatty acid oxidation is increased, increasing the oxygen requirement per ATP molecule produced. A major factor in the development and progression of heart failure is an already reduced availability of ATP, determining a metabolic state that has been defined as energy starvation ${ }^{13}$.

\section{Limitations}

The small number of study patients and the lack of a control group are the major limitations of the study. Since heart failure is a continually progressive process of autonomic imbalance, it is difficult to find the reference

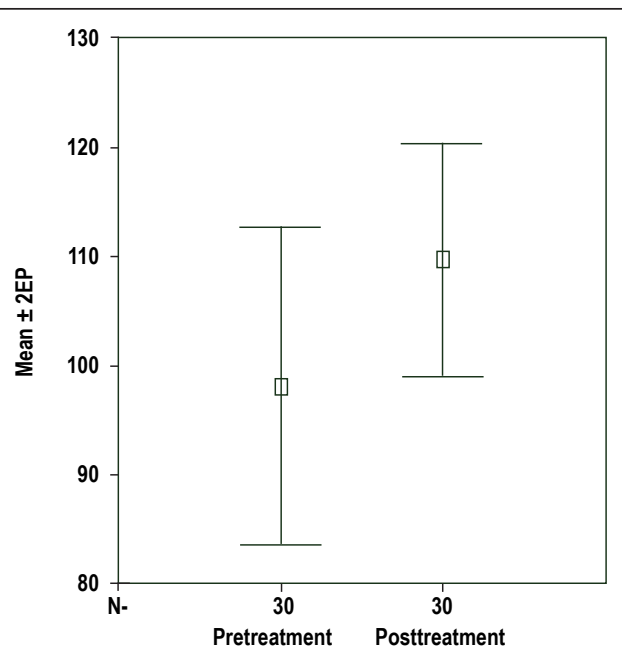

SE: Standard error, SDNN: Standard deviation of all normal-to-normal intervals

Figure 1 - Error bars for SDNN; before and after treatment with trimetazidine.

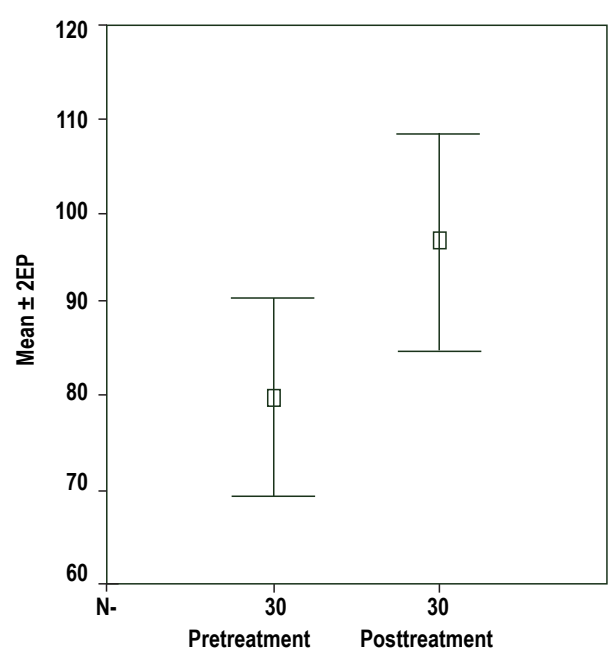

SE: Standard error, SDANN: Standard deviation of mean of all normal-to-normal intervals

Figure 2 - Error bars for SDANN; before and after treatment with trimetazidine.

point to define the timing of HRV measurement in heart failure patients. Comparisons of HRV determined in heart failure patients with similar clinical conditions in all populations are also difficult. It is possible that these limitations may be the cause of the variation and disparity in HRV predictive values. Therefore, instead of a placebo controlled study, progressive changes in measurements of HRV would be more important.

\section{Conclusions}

Trimetazidine, when added to optimal medical therapy in patients with heart failure of ischemic origin, may improve heart rate variability in association with improved 
left ventricular ejection fraction. Long-term and larger sample studies are necessary to evaluate whether these findings may have clinical implications on mortality and morbidity.

\section{Potential Conflict of Interest}

No potential conflict of interest relevant to this article was reported.

\section{References}

1. Cohn JN, Levine TB, Olivari MT. Plasma norepinephrine as a guide to prognosis in patients with chronic congestive heart failure. N Engl J Med. 1984; 311 (13): 819-23.

2. Nolan J, Flapan AD, Capewell S, MacDonald T, Neilson JMM, Ewing DJ. Decreased cardiac parasympathetic activity in chronic heart failure and its relation to left ventricular function. Br Heart J. 1992; 67: 482-6.

3. Nolan J, Flapan AD, Goodefield NE, Prescott RJ, Bloomfield P, Neilson JMM, et al. Measurement of parasympathetic activity from 24-hour ambulatory electrocardiograms and its reproducibility and sensitivity in normal subjects, patients with symptomatic myocardial ischemia, and patients with diabetes mellitus. Am J Cardiol. 1996; 77: 154-8.

4. Chattipakorn N, Incharoen T, Kanlop N, Chattipakorn S. Heart rate variability in myocardial infarction and heart failure: review. Int J Cardiol. 2007; 120: 289-96.

5. Paschoal MA, Polessi EA, Simioni FC. Evaluation of heart rate variability in trained and sedentary climacteric women. Arq Bras Cardiol. 2008; 90: 74-9.

6. Pinheiro $\mathrm{CH}$, Medeiros RA, Pinheiro DG, Marinho Mde J. Spontaneous respiratory modulation improves cardiovascular control in essential hypertension. Arq Bras Cardiol. 2007; 88: 651-9.

7. Nolan J, Batin PD, Andrews R, Lindsay SJ, Brooksby P, Mullen M, et al. Prospective study of heart rate variability and mortality in chronic heart failure: results of the United Kingdom Heart Failure Evaluation and Assessment of Risk Trial (UK-Heart). Circulation. 1998; 98: 1510-6.

8. Yi G, Goldman JH, Keeling PJ, Reardon M, McKenna WJ, Malik M. Heart rate variability in idiopathic dilated cardiomyopathy: relation to disease severity and prognosis. Heart. 1997; 77: 108-14.

9. Binkley PF, Haas GJ, Starling RC, Nunziata E, Hatton PA, Leier CV, et al. Sustained augmentation of parasympathetic tone with angiotensin-converting enzyme inhibition in patients with congestive heart failure. J Am Coll Cardiol. $1993 ; 21: 655-61$.

10. Bullinga JR, Alharethi R, Schram MS, Bristow MR, GilbertE. Changes in heart rate variability are correlated to hemodynamic improvement with chronic carvedilol therapy in heart failure. J Card Fail. 2005; 11: 693-9.

11. Ulgen MS, Akdemir O, Toprak N. The effects of trimetazidine on heart rate variability and signal-averaged electrocardiography in early period of acute myocardial infarction. Int J Cardiol. 2001; 77: 255-62.

12. Guler N, Eryonucu B, Gunes A, Guntekin U, Tuncer M, Ozbek H. Effects of trimetazidine on submaximal exercise test in patients with acute myocardial infarction. Cardiovasc Drugs Ther. 2003; 17: 371-4.

13. Katz AM. Is the failing heart energy depleted? Cardiol Clin. 1998; 16: 633-44.

14. Lang RM, Bierig M, Devereux RB, Flachskampf FA, Foster E, Pellikka PA, et al. Recommendations for chamber quantification: a report from the American Society of Echocardiography's Guidelines and Standards Committee and the Chamber Quantification Writing Group, developed in conjunction with the European Association of Echocardiography, a branch of the European Society of Cardiology. J Am Soc Echocardiogr. 2005; 18: 1440-63.

15. Bittencourt MI, Benchimol Barbosa PR, Drumond Neto C, Bedirian R, Barbosa EC, Brasil F, et al. Assessing autonomic function in hypertrophic cardiomyopathy. Arq Bras Cardiol. 2005; 85: 388-96.

16. Menezes Ada S Jr, Moreira HG, Daher MT. Analysis of heart rate variability

\section{Sources of Funding}

There were no external funding sources for this study.

\section{Study Association}

This study is not associated with any post-graduation program. in hypertensive patients before and after treatment with angiotensin IIconverting enzyme inhibitors. Arq Bras Cardiol. 2004; 83: 169-72.

17. Kleiger RE, Miller JF, Bigger JT Jr, Moss AJ. The multicenter post infarction research group. Decreased heart rate variability and its association with increased mortality after acute myocardial infarction. Am J Cardiol. 1987; 59: 256-62.

18. Topal E, Ozdemir R, Barutcu I, Aksoy Y, Sincer I, Akturk E, et al. The effects of trimetazidine on heart rate variability in patients with slow coronary artery flow. J Electrocardiol. 2006; 39: 211-8.

19. Szabo B, van Veldhuisen DJ, van der Veer N, Brouwer J, De Graeff PA, Crijns $\mathrm{HJ}$. Prognostic value of heart rate variability in chronic congestive heart failure secondary to idiopathic or ischemic dilated cardiomyopathy. Am J Cardiol. 1997; 79 (7): 978-80.

20. Fragasso G, Palloshi A, Puccetti P, Silipigni C, Rossodivita A, Pala M, et al. A randomized clinical trial of trimetazidine, a partial free fatty acid oxidation inhibitor, in patients with heart failure. J Am Coll Cardiol. 2006; 48: 992-8.

21. Sisakian H, Torgomyan A, Barkhudaryan A. The effect of trimetazidine on left ventricular systolic function and physical tolerance in patients with ischaemic cardiomyopathy. Acta Cardiol. 2007; 62: 493-9.

22. Fragasso G, Piatti PM, Monti L, Palloshi A, Setola E, Puccetti P, et al. Short and long term beneficial effects of trimetazidine in patients with diabetes and ischaemic cardiomyopathy. Am Heart J. 2003; 146: E1-E8.

23. Birand A, Kudabierdieva GZ, Batyraliev TA, Akgul F, Usal A. Effects of trimetazidine on heart rate variability and left ventricular systolic performance in patients with coronary artery disease after percutaneous transluminal angioplasty. Angiology. 1997; 48: 413-22.

24. Aronson D, Mittleman MA, Burger AJ. Measures of heart period variability as predictors of mortality in hospitalized patients with decompensated congestive heart failure. Am J Cardiol. 2004; 93: 59-63.

25. Shlyakhto EV, Almazov VV, Nifontov EM, Vakhrameyeva IV, Rudomanov OG, Zakharov DV, et al. Antianginal effects of trimetazidine and left ventricular function improvement in patients with stable angina pectoris. Am J Cardiovasc Drugs. 2002; 2: 119-24.

26. Bricaud H, Brottier L, Barat JL, Combe C, Boussens B, Bonnet J. Cardioprotective effects of trimetazidine in severe ischemic cardiomyopathy. Cardiovasc Drugs Ther. 1990; 4: 861-5.

27. Marzilli M. Cardioprotective effects of trimetazidine: a review. Curr Med Res Opin. 2003; 19: 661-72.

28. Lopaschuk GD, Stanley WA, Lopaschuk CC. Metabolic approach in heartfailure: the rationale for metabolic interventions. Heart Metab. 2005; 27: 5-10.

29. Fragasso G, Spoladore R, Bassanelli G, Cuko A, Montano C, Salerno A, et al. New directions in the treatment of heart failure: targeting free fatty acid oxidation. Curr Heart Fail Rep. 2007; 4: 236-42.

30. Lagadic-Gossmann D, Le Prigent K, Feuvray D. Effects of trimetazidine on pHi in the rat isolated ventricular myocyte. Br J Pharmacol. 1996; 117: 831-8.

31. Renaud JF. Internal $\mathrm{pH}, \mathrm{Na}^{+}$, and $\mathrm{Ca}^{2}$ regulation by trimetazidine during cardiac cell acidosis. Cardiovasc Drugs Ther. 1988; 1: 677-86.

32. Wolff AA, Rotmensch HH, Stanley WC, Ferrari R. Metabolic approaches to the treatment of ischemic heart disease: the clinicians' perspective. Heart Fail Rev. 2002; 7: 187-203. 